NASA/TM-2012-217702

\title{
Development of 3-D Ice Accretion Measurement Method
}

\author{
Sam Lee \\ ASRC Aerospace, Inc., Cleveland, Ohio \\ Andy P. Broeren and Harold E. Addy, Jr. \\ Glenn Research Center, Cleveland, Ohio \\ Robert Sills \\ Sierra Lobo, Inc., Fremont, Ohio \\ Ellen M. Pifer \\ St. Louis University, St. Louis, Missouri
}




\section{NASA STI Program . . . in Profile}

Since its founding, NASA has been dedicated to the advancement of aeronautics and space science. The NASA Scientific and Technical Information (STI) program plays a key part in helping NASA maintain this important role.

The NASA STI Program operates under the auspices of the Agency Chief Information Officer. It collects, organizes, provides for archiving, and disseminates NASA's STI. The NASA STI program provides access to the NASA Aeronautics and Space Database and its public interface, the NASA Technical Reports Server, thus providing one of the largest collections of aeronautical and space science STI in the world. Results are published in both non-NASA channels and by NASA in the NASA STI Report Series, which includes the following report types:

- TECHNICAL PUBLICATION. Reports of completed research or a major significant phase of research that present the results of NASA programs and include extensive data or theoretical analysis. Includes compilations of significant scientific and technical data and information deemed to be of continuing reference value. NASA counterpart of peer-reviewed formal professional papers but has less stringent limitations on manuscript length and extent of graphic presentations.

- TECHNICAL MEMORANDUM. Scientific and technical findings that are preliminary or of specialized interest, e.g., quick release reports, working papers, and bibliographies that contain minimal annotation. Does not contain extensive analysis.

- CONTRACTOR REPORT. Scientific and technical findings by NASA-sponsored contractors and grantees.
- CONFERENCE PUBLICATION. Collected papers from scientific and technical conferences, symposia, seminars, or other meetings sponsored or cosponsored by NASA.

- SPECIAL PUBLICATION. Scientific, technical, or historical information from NASA programs, projects, and missions, often concerned with subjects having substantial public interest.

- TECHNICAL TRANSLATION. Englishlanguage translations of foreign scientific and technical material pertinent to NASA's mission.

Specialized services also include creating custom thesauri, building customized databases, organizing and publishing research results.

For more information about the NASA STI program, see the following:

- Access the NASA STI program home page at http://www.sti.nasa.gov

- E-mail your question to help@sti.nasa.gov

- Fax your question to the NASA STI Information Desk at 443-757-5803

- Phone the NASA STI Information Desk at 443-757-5802

- Write to: STI Information Desk NASA Center for AeroSpace Information 7115 Standard Drive Hanover, MD 21076-1320 
NASA/TM-2012-217702

\title{
Development of 3-D Ice Accretion Measurement Method
}

\author{
Sam Lee \\ ASRC Aerospace, Inc., Cleveland, Ohio \\ Andy P. Broeren and Harold E. Addy, Jr. \\ Glenn Research Center, Cleveland, Ohio \\ Robert Sills \\ Sierra Lobo, Inc., Fremont, Ohio \\ Ellen M. Pifer \\ St. Louis University, St. Louis, Missouri
}

Prepared for the

Atmospheric and Space Environments Conference

sponsored by the American Institute of Aeronautics and Astronautics

New Orleans, Louisiana, June 25-28, 2012

National Aeronautics and

Space Administration

Glenn Research Center

Cleveland, Ohio 44135 


\section{Acknowledgments}

This work was funded by NASA Atmospheric Environment Safety Technologies Project and Aeronautics Test Program. The authors would like to thank the Icing Research Tunnel personnel and Dr. Judith VanZante. The authors would also like to thank the representatives from the scanner manufacturers for demonstrating their systems in the IRT and assisting in the post-processing of the data.

Trade names and trademarks are used in this report for identification only. Their usage does not constitute an official endorsement, either expressed or implied, by the National Aeronautics and Space Administration.

Level of Review: This material has been technically reviewed by technical management.

Available from

NASA Center for Aerospace Information 7115 Standard Drive

Hanover, MD 21076-1320
National Technical Information Service 5301 Shawnee Road Alexandria, VA 22312

Available electronically at http://www.sti.nasa.gov 


\title{
Development of 3-D Ice Accretion Measurement Method
}

\author{
Sam Lee \\ ASRC Aerospace, Inc. \\ Cleveland, Ohio 44135 \\ Andy P. Broeren and Harold E. Addy, Jr. \\ National Aeronautics and Space Administration \\ Glenn Research Center \\ Cleveland, Ohio 44135 \\ Robert Sills \\ Sierra Lobo, Inc. \\ Fremont, Ohio 43420 \\ Ellen M. Pifer \\ St. Louis University \\ St. Louis, Missouri 63103
}

\begin{abstract}
A research plan is currently being implemented by NASA to develop and validate the use of a commercial laser scanner to record and archive fully three-dimensional (3-D) ice shapes from an icing wind tunnel. The plan focused specifically upon measuring ice accreted in the NASA Icing Research Tunnel (IRT). The plan was divided into two phases. The first phase was the identification and selection of the laser scanning system and the post-processing software to purchase and develop further. The second phase was the implementation and validation of the selected system through a series of icing and aerodynamic tests. Phase I of the research plan has been completed. It consisted of evaluating several scanning hardware and software systems against an established selection criteria through demonstrations in the IRT. The results of Phase I showed that all of the scanning systems that were evaluated were equally capable of scanning ice shapes. The factors that differentiated the scanners were ease of use and the ability to operate in a wide range of IRT environmental conditions.
\end{abstract}

\section{Nomenclature}

AEST Atmospheric Environment Safety Technologies

IRT Icing Research Tunnel

LWC liquid water content

MVD median volumetric diameter

RPM rapid prototype method

SLA stereolithography

SLD supercooled large droplet

SLS selective laser sintering

$T_{0} \quad$ total air temperature

$t \quad$ icing spray time

$V \quad$ tunnel airspeed

$\alpha \quad$ angle of attack 


\section{Introduction}

Icing wind tunnels are designed to simulate in-flight icing environments and will ideally conform to published standards for calibration and operations to ensure confidence in the environmental simulation (Ref. 1). The chief product of such facilities is the ice accretion that forms on various test articles ranging from airplane wings, rotor blades, engine inlets, radomes and other flight hardware. Bosetti et al. (Ref. 2) discuss many important aspects of documenting ice-shape characterization. They point out that ice shapes are often used by other groups for follow-on computational or experimental aerodynamic studies; development of design criteria or requirements; engineering tool development, improvement or validation. Broeren et al. (Ref. 3) describe a recently completed comprehensive study of aerodynamic simulation of ice accretion. For some cases such as initial roughness, spanwise ridges and streamwise type ice shapes, the fine geometric details can be important to the resulting aerodynamics. Therefore, documentation of the resulting ice accretion is a key piece of data in icing-wind-tunnel tests.

There are a number of currently used options for documenting ice accretion in icing-wind-tunnel testing. They range from simple photographs and pencil tracings to mold and casting methods. Quantitative photography has also been used in order to extract roughness size characteristics (Refs. 4 and 5). While all of these methods provide useful data, there are many limitations. Simple photographs provide excellent qualitative information, but very little quantitative data about the ice accretion. Quantitative photography requires multiple cameras or camera locations, calibration against static grids and labor intensive data reduction (Ref. 6). It may not be appropriate for very complex ice accretion with areas obscured from optical access. The most commonly used method is most likely the cross-sectional tracing. Depicted in Figure 1, this method requires melting a section of the ice accretion, inserting a cardboard template and tracing around the shape. While this method is relatively fast and simple, there can be variations in the results due to individual tracing techniques and subsequent digitization procedure. The latter task can also require significant post-test time, particularly for large and complex ice cross-sections. The tracing is only a two-dimensional (2-D) piece of information. Many ice accretions, particularly on swept wings are highly three-dimensional (3-D). Bosetti et al. (Ref. 2) show a comparison of three tracings of the same ice shape along the span of a wing. There were significant differences in these tracings. The best current technology for capturing 3-D features of ice accretion is the mold and casting method. This has been used for many years, but was improved at NASA Glenn (then Lewis) during the 1980s using more robust materials to improve accuracy and durability (Ref. 7). The main disadvantages to the mold and casting method are that it can be time consuming both during the icing test and in post-test production. Cost can be significant in some cases, but generally scales with the size of the ice accretion to be documented. What is needed is a method to accurately and efficiently digitize ice accretion in 3-D.

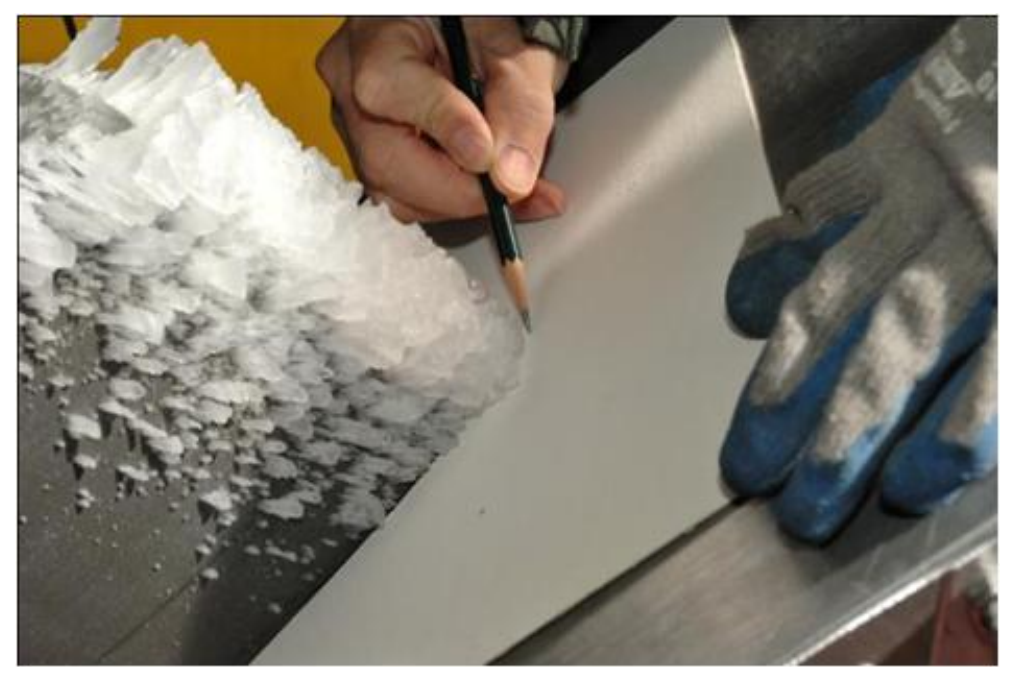

Figure 1.—Cross-sectional ice shape tracing method. 
Laser-based and other optical scanning methods have been investigated to accomplish 3-D digitization of ice accretion. In 2004, Broughton (Ref. 8) provided background information and a corresponding research plan to develop a stationary bench-top laser scanning system at the NASA Glenn Research Center. While the system was successfully used to digitize ice accretion, there were a number of challenges associated with processing the raw point cloud data into a closed surface that accurately represented the ice accretion. A closed surface is critical for most follow-on work such as computational or experimental aerodynamic analysis. More recent research in other fields indicated that new advances in scanning technology and data processing software were improved such that complex 3-D point cloud data could be acquired and closed to form a "water tight" surface (Refs. 9 and 10). Given these advances in technology and the motivations described earlier in this Introduction, NASA has incorporated development of 3-D ice accretion digitization methods into its current research plans.

The main goal of the Airframe Icing Technical Challenge of the Atmospheric Environment Safety Technologies Project of the NASA Aviation Safety Program is to achieve acceptance of experimental and computational icing simulation tools in supercooled large droplet (SLD) conditions and on 3-D airframe components, including swept wings (Refs. 11 and 12). Since this goal focuses on 3-D geometries, it is necessary to develop a suitable means of recording and archiving fully $3-\mathrm{D}$ descriptions of experimental ice accretion geometry. A research plan to develop this capability was introduced in the NASA Aviation Safety Program Technical Meeting in 2011 (Ref. 13). This research was divided into two phases. The first phase considered selection of a laser-scanning system and software. This has been completed and the results are described in this paper. The second phase considers validation of the system and a declaration of capability for use in future icing experiments. These plans are discussed at the end of this paper.

The roadmap of Phase I is shown in Figure 2. There are numerous commercial 3-D laser scanning systems and post-processing software available in the market. It was necessary to develop a process to identify the most appropriate system for purchase and further development. Parallel plans were developed to identify the most suitable scanner hardware and software systems.

The first task in the plan was to define the criteria that was used to evaluate the scanner hardware and software. The hardware selection criteria were based on the ability of the scanner to operate in the IRT test section environment under a wide range of temperature and humidity conditions and the ability of the system to scan various types of ice accretion. The software selection criteria were based on the compatibility of the software with various scanners that were evaluated and the ability to process the data effectively and efficiently. The selection criteria (for both hardware and software) will be described in more detail later in the paper.

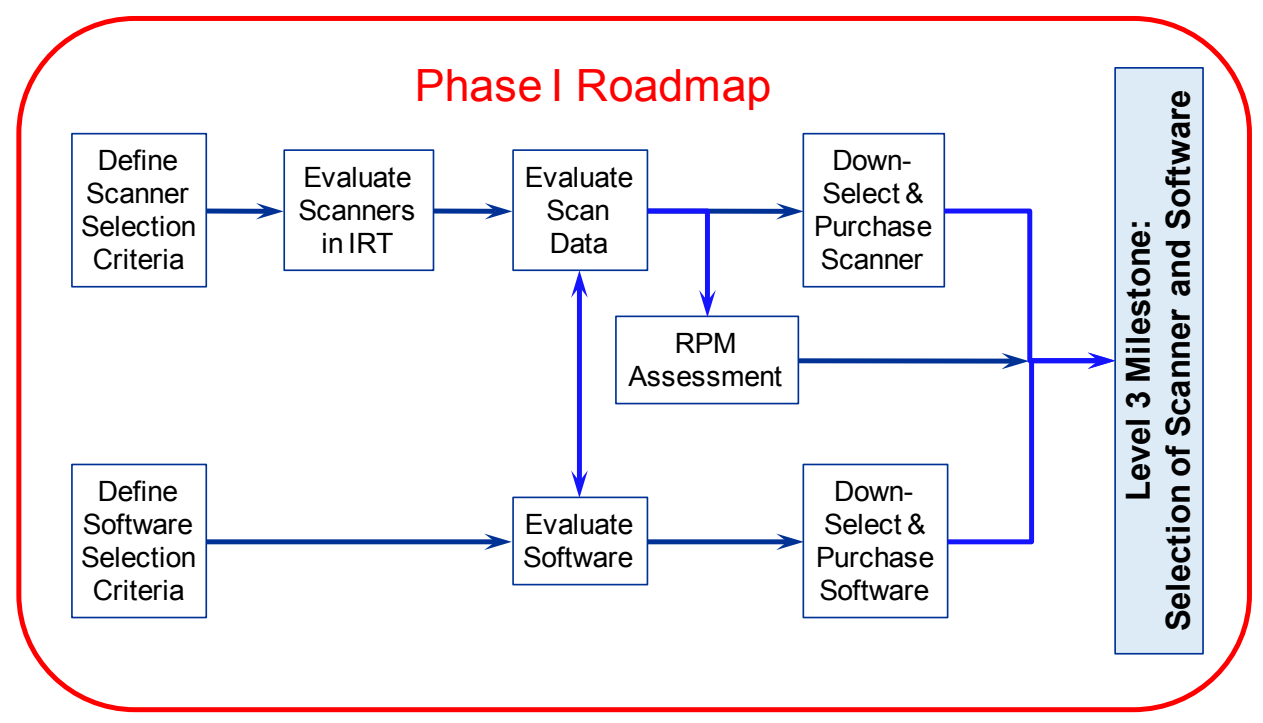

Figure 2.-Phase I of the research plan. 
Several scanner manufacturers were invited to demonstrate the capability of their scanners in the IRT test section environment. The evaluation procedure was established such that the scanners were judged against the selection criteria. Identical evaluation processes were used when possible, and the scanners were operated in a wide range of tunnel conditions and scanned a wide range of ice shape types. The results of the IRT scanner evaluation and software evaluation were used to identify the most capable and promising system for further development.

Also included in Phase I was the assessment of the current rapid prototype methods that will be used to manufacture the ice shapes from the 3-D scan data. Scan data of ice accretion were processed into water-tight surfaces, and various RPM (rapid-prototype model) methods were evaluated to ascertain the current state of capability to manufacture artificial ice shapes. The outcome of the Phase I of the research plan was the selection of the scanner and software to purchase for further development. The results of the Phase I of the research plan is detailed in this paper.

\section{Software and Scanner Selection Methodology}

The methodology used in Phase I of the research plan to evaluate and down-select a scanner hardware system and scanning software is detailed in this section.

\section{Scanner and Software Selection Criteria}

In order to evaluate the candidate scanner hardware and software systems, a list of selection criteria and questions were developed. The software selection criteria consisted of four main categories: Scanner Compatibility, Water-Tight Modeling Ability, Noise Filtering, and Efficiency. The Scanner Compatibility category was used to determine if the software was compatible with the scanning hardware being evaluated. Depending on the ice shapes, the scan data were expected to have significant amounts of the gaps and holes. The ability of the software to fill and close these gaps and holes was evaluated using the Water-Tight Modeling category. The Noise Filtering category was used to evaluate how well the software filters and removes noise in the raw scan data without altering the important features of the ice shape. Finally, the Efficiency category was used to assess the speed, processing time, and ease of use of the software.

\section{Selection Criteria-Software}

1. Scanner compatibility-The software was expected to be purchased prior to scanner selection and be used to evaluate the candidate scanners. Can the software work with scanners being considered?

2. Water-tight modeling ability-The software will be used to convert the point clouds generated by the scanner into a water-tight surface model. How effective is the software in minimizing gaps and holes? How well does the scanner fill in these gaps and holes? How much user intervention is required in filling these holes?

3. Noise filtering - There is expected to be some noise in the raw point cloud (i.e., outliers). How well does the software remove these points without making the surface too smooth or round?

4. Efficiency (ease of use, speed, processing time, large file capability) - The process of converting the scanned point cloud into a water-tight model should be automated as much as possible with the least amount of user intervention. The software should also be easy to use. How much computer processing time does it take to convert a point cloud into a water-tight surface? What is the largest, most detailed ice shape the software can render?

5. Cost versus capability (final judgment call) - Capabilities of the software will drive the selection. However, if one system costs substantially less with minimal reduction in capability, this may be considered. 
The hardware selection criteria consisted of two main categories: IRT Test Section Capability and Scanning Capability. As part of the IRT Test Section Capability category the usability of the scanner was assessed. The scanner should be easily set up and operated by a single user, with a minimal amount of pre-scanning preparatory work. The Scanning Capability category was used to evaluate the ability of the system to scan the ice accretion. Some of the criteria in this category were the scan resolution, scan speed, ability to scan gaps and holes, and accuracy.

\section{Selection Criteria-Hardware}

1. IRT test section capability

a. Environment-The temperature ranges from $32^{\circ} \mathrm{F}$ down to $0{ }^{\circ} \mathrm{F}$. The relative humidity can range up to 100 percent. This environment must not affect accuracy and durability of the scanner.

b. Usability

(1) Portability-It is expected that the scanner will be moved into test section for the scans and removed from the test section during the icing runs. It should be portable enough for one person to easily move in and out of the test section.

(2) Ease of Use - The scanner should easily be operated by one user. The scanner should be aimed at the target easily by the operator. There should be a real-time feedback of scanning status through a computer display.

(3) Convenience of Measurement Procedure-How difficult and time consuming is the scanner setup procedure. Does the scanner need reference points on the model/ice accretion? Are reference hard points needed? Are any special steps needed in the set-up process? Does it require painting the ice?

2. Scanning Capability

a. Scan resolution

b. Scan speed (per resolution and volume) - How long does the scanner take to scan a given volume at a given resolution? A typical scan volume is expected to be 24 - by 12 - by 12 -in.

c. Ability to scan gaps and holes-A significant issue with laser-based scanner is its ability to "see" into gaps and holes. How far into gaps and holes can the scanner measure? This will be function of gap/hole size and may be depended on type of ice.

d. Accuracy-How accurate is the scanner? This may be tested on metal calibration block and metal "roughness sample" block of known dimensions.

3. Cost versus capability (final judgment call) —Capabilities of the scanner will be the most important criteria in the selection. However, if one system costs substantially less with minimal reduction in capability, this may be considered.

\section{Software Evaluation}

During the formulation of the research plan, a thorough evaluation and comparison of several commercially available 3-D scanning software was planned. However, during the early stage of Phase I of the plan, it was clear that this was not possible due to cost and time constraints. This would have required purchasing and becoming proficient on all of the software that were being considered. Instead, two most widely used software packages were considered, Geomagic and Polyworks. Both of these software packages were found to be compatible with all of the scanners that were being evaluated. The most critical factor in the software selection criteria was the ability to create water-tight surfaces from the scan data. Conversations with the scanner factory representatives during the scanner demonstrations indicated that Geomagic is better able to process and generate water-tight surfaces of "organic" shapes typical of ice accretion shapes. Also, the Facilities Division at NASA Glenn currently uses Geomagic, and could provide expertise and on-site support. This led to the decision to select Geomagic as the scanning software. 


\section{Hardware Evaluation}

\section{IRT Test Procedure}

All of the scanners were evaluated in NASA Glenn Icing Research Tunnel. The IRT is capable of generating a wide range of icing conditions in both Appendix C and SLD. It has a test section that measures 9- by 6-ft with speeds of up to $390 \mathrm{mph}$. The tunnel can be operated at temperatures between -20 and $33^{\circ} \mathrm{F}$. A turntable mounted on the floor of the test section was used to set the airfoil model angle of attack. A more detailed description of the facility can be found in the IRT user manual (Ref. 14).

For the scanner evaluation, three straight wing ice shapes identified in the ice shape characterization study by Bragg, et al. (Ref. 15) were chosen: horn ice, roughness, and streamwise ice. A swept wing scallop ice shape was also chosen. A full-span 21-in. chord NACA 0012 model was used for the three straight wing ice shapes and a 36-in. chord semi span NACA 0012 model set to $45^{\circ}$ sweep was used for the scallop ice shape. Three scanning systems were evaluated in spring 2011 using these ice shapes.

The IRT scanner evaluation procedure consisted of the following six steps:

1. Accrete ice on the test article

2. Photograph the ice

3. Spray the ice with white paint

4. Install and set up the scanner

5. Scan the ice shape

6. Make hand tracings of the ice shape

The first step was to accrete the ice on the test article using predetermined tunnel and spray setting. The icing conditions used for the scanner evaluation are shown in Table 1. After the ice was accreted, it was photographed to visually document the features for later comparisons to the scan data. A critical step in the scanning procedure was the treatment of the ice surface. Due to the transparent and refractive nature of ice, the accreted shape must be coated with highly-reflective, diffuse, white paint. Painting the ice allows the scanner optics to pick out the surface features of the accreted shape. Even ice that appear to be fully opaque (such as rime ice) could not be scanned unless the surface was treated. A titanium-dioxide based paint was developed for this purpose and was applied using an airbrush, as shown in Figure 3(a). Figure 3(b) shows the painted ice on top and unpainted ice on the bottom. The scanner was then brought into the test section and set up, as shown in Figure 4. The ice was scanned until sufficient level of detail had been captured over the airfoil model in the center $1 \mathrm{ft}$ section of the test section. A final step in the procedure was to record a pencil tracing of a cross-section cut. Currently pencil tracings are the primary means of recording $2-\mathrm{D}$ ice shapes in the IRT, and they served as a reference to check the accuracy of the scanning system. Typically, it required approximately 20 min to paint the ice, set up the scanner, and scan the ice. For comparison, hand tracing of the ice shape at one spanwise location took approximately $10 \mathrm{~min}$.

TABLE 1.-SCANNER EVALUATION ICING CONDITIONS.

\begin{tabular}{|l|c|c|c|c|c|c|}
\hline \multicolumn{1}{|c|}{ Ice Type } & $\begin{array}{c}V, \\
\mathrm{kn}\end{array}$ & $\begin{array}{c}\alpha, \\
\circ\end{array}$ & $\begin{array}{c}\text { MVD, } \\
\mu \mathrm{m}\end{array}$ & $\begin{array}{c}\mathrm{LWC}, \\
\mathrm{g} / \mathrm{m}^{3}\end{array}$ & $\begin{array}{c}T_{0}, \\
{ }^{\circ} \mathrm{F}\end{array}$ & $\begin{array}{c}t, \\
\min \end{array}$ \\
\hline Horn & 200 & 4 & 20 & 0.55 & 25 & 7 \\
\hline Streamwise & 200 & 4 & 20 & 0.55 & 1 & 7 \\
\hline Roughness & 200 & 4 & 20 & 0.55 & 25 & 1 \\
\hline 3-D Scallop & 200 & 0 & 32 & 0.45 & 20 & 19.9 \\
\hline
\end{tabular}




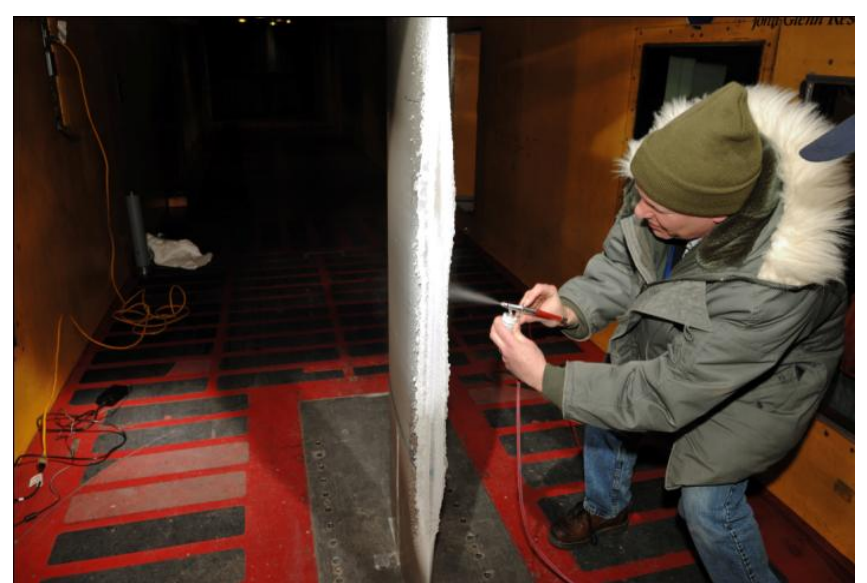

(a)

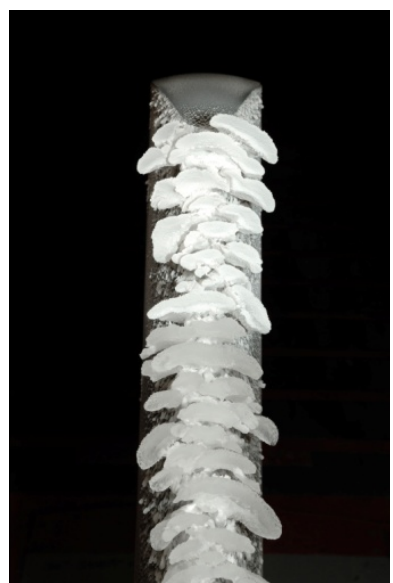

(b)

Figure 3.-Painting the ice prior to scanning. (a) Applying paint $\quad$ (b) Painted ice.
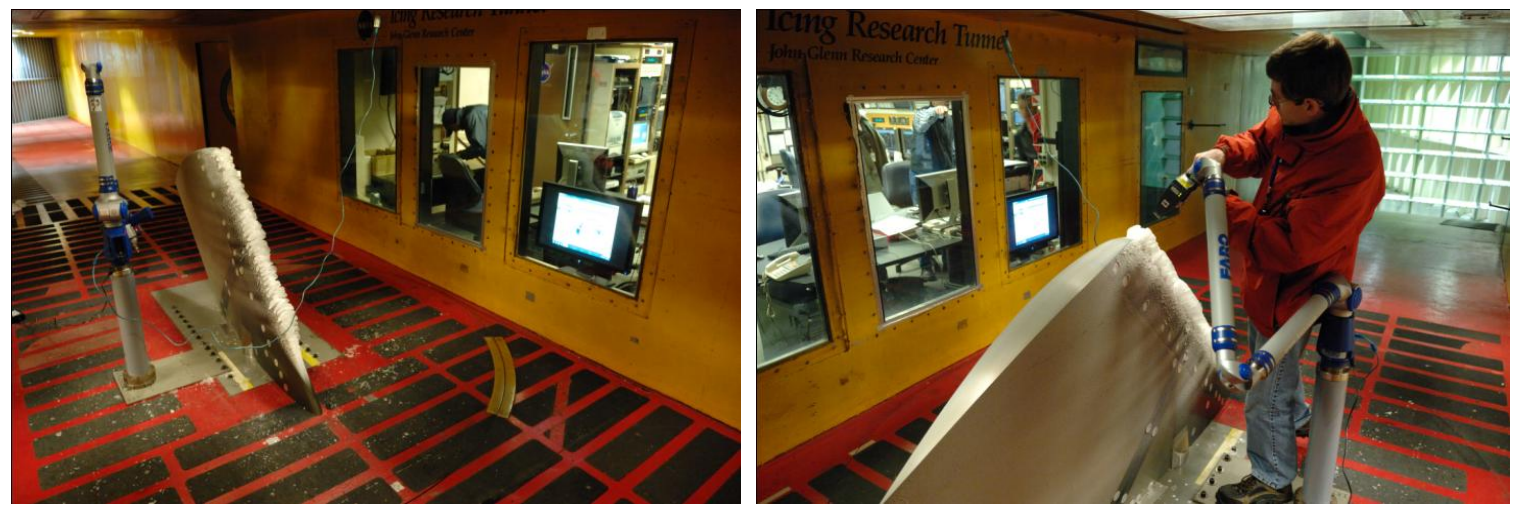

Figure 4.-Scanning ice in the test section

\section{Scanners Evaluated}

Three laser scanners were evaluated in the IRT during spring 2011 using the procedure described above. They were Faro Quantum, Romer Absolute SI, and NVision HandHeld. They were all arm-based laser scanning systems. The laser scan head was mounted on the end of a seven-axis arm which in turn was attached to the floor of the tunnel test section using a magnetic base. The operator positioned the scan head manually, and the encoders built into the arm tracked the location of the scanner head relative to the base of the arm. The scan data from the arm-based scanners were referenced to the location of the base of the arm. General specifications of the three arm-based scanners are shown in Table 2. All three of the arms could be fitted with a hard-probe for single point measurements.

TABLE 2.-SCANNER SYSTEM GENERAL SPECIFICATIONS

\begin{tabular}{|l|c|c|c|c|c|c|c|}
\hline Manufacturer & Model & Type & $\begin{array}{c}\text { Max. line } \\
\text { resolution, } \\
\text { in. }\end{array}$ & $\begin{array}{c}\text { Line width, } \\
\text { in. }\end{array}$ & $\begin{array}{c}\text { Scan rate, } \\
\text { Hz }\end{array}$ & $\begin{array}{c}\text { Arm encoder } \\
\text { type }\end{array}$ & $\begin{array}{c}\text { Geomagic } \\
\text { plug-in }\end{array}$ \\
\hline Faro & Quantum & Arm & 0.002 & 2.5 & 30 & Relative & Yes \\
\hline Romer & Absolute & Arm & 0.002 & 2 & 30 & Absolute & Yes \\
\hline NVision & HandHeld & Arm & 0.002 & 2 & 30 & Absolute & No \\
\hline Creaform & HandyScan & Armless & 0.002 & 2.5 & 25 & N/A & Yes \\
\hline Creaform & MetraScan & Armless & 0.002 & 2.7 & 25 & N/A & Yes \\
\hline
\end{tabular}

The Faro Quantum arm was owned by NASA Glenn's Facilities Division and was operated by NASA personnel during the evaluation. At the time of the evaluation, it had been updated in the Faro lineup with 
another model, but was considered similar enough to be a good representation of the newer model. The body of the arm was made of aluminum and used a built in temperature senor to compensate for the expansion/contraction of the tube. The arm is capable of compensating for a change in temperature of $0.6^{\circ} \mathrm{C} / \mathrm{min}$. The arm used relative position encoders, which required the arm be put through its full range of motion prior to use. The Faro arm could be operated directly from Geomagic through the use of a plug-in.

The Romer Absolute SI was a seven-axis arm with a laser scanner built into the handle. The arm was constructed of thermally stable carbon fiber and did not require any thermal compensation. The system also employed absolute position encoders, so a ranging of the arm was not required prior to use. The Romer arm could be operated directly from Geomagic through a plug-in.

The NVision HandHeld system used a Romer arm with an NVision scanner head that was attached to the arm handle. Like the Absolute system, it used a carbon fiber arm with absolute encoders and did not require any thermal compensation. The NVision system could not be operated directly from Geomagic since a plug-in was not available and required the use of a proprietary software. However, the scan data could be processed by Geomagic after the scan was completed.

\section{Prior Evaluation}

Two scanning systems manufactured by Creaform were evaluated as well, but not as part of the standardized evaluation process described above. The first was the HandyScan system, which was evaluated during an IRT icing test demonstration in 2008. The MetraScan system was evaluated in the summer of 2011. The IRT was undergoing a renovation at that time so the evaluation of the MetraScan system was performed with ice castings attached to the leading edge of an airfoil model (which served to simulate ice accretions on test article).

Both HandyScan and MetraScan did not require the use of an arm for positioning, allowing much greater range of motion for the scanner. The HandyScan system used reflective targeting dots on the scanned objects for positioning. The scan data from the HandyScan were referenced to these targeting dots. The MetraScan system used a "C-Track" base that tracked the position of the laser scanner optically using reflective dots on the scanner itself. The scan data from the MetraScan were referenced to the location of the "C-track". Both Creaform scanners could be operated directly from Geomagic through the use of plug-ins. General specifications of the two Creaform scanners are shown in Table 2 as well.

\section{Software and Scanner Evaluation Results}

\section{Scanner Comparison}

The purpose of the scanner evaluation was not to determine whether one system is generally superior to another. The scanners were evaluated against a very specific set of criteria related to digitization of ice shapes in the IRT test section. This also meant operating the scanners in an environment that was well outside of their designed operating parameters, especially in temperature. The down-selection process was used to identify a scanner that best supported the very specific needs of NASA for use in the IRT. The findings detailed below should not be viewed as a determination by NASA of one system being superior to another for general use.

One of the findings during the scanner evaluation was that the quality of the ice shape scan depended greatly on the experience of the scanner operator. None of the company representatives that demonstrated the scanners had experience scanning ice shapes. The scanners are normally used to reverse engineer items with smooth, regular features in a shop environment. They are not typically used to scan rough, irregular shapes in a below freezing environment. All of the scanners demonstrated were able to scan ice shapes (or simulations) in the IRT test section. However the quality of the ice shape scans differed among the scanners evaluated. Since all of the scanners operate on the same principle (and have very similar specifications, as shown in Table 2), the differences were attributed to operator variations, rather than scanner hardware differences. The highest quality scans were obtained with the Faro arm, but this was 
likely due to the fact that it was operated by a NASA engineer who had previous experience scanning ice shapes in IRT. Because of this, most of the emphasis on the scanner evaluation was placed on usability, operability, and software.

The arm-based systems and the two Creaform scanners required different set-up procedures for use in the IRT and had different operational issues and limitations. The Creaform HandyScan system required reflective reference targets near the objects to be scanned (in this case the ice accretion shapes). The reference targets could not be placed directly on the ice, so a wired mesh had to be constructed around the ice shape, and the reference targets were placed on the wire mesh (as shown in Figure 5). This wire mesh had to be installed after each icing spray before the ice shape could be scanned. Different wire-mesh configurations would also need to be constructed for different airfoil models that are tested in the IRT.

The Creaform MetraScan system did not require the use of reflective reference targets near the ice shapes. However, because the C-track had to be located outside of the tunnel test section due to temperature limitations, a large access panel had to be created on the test section ceiling (Figure 6). This was required to provide a clear line of site between the C-track and the handheld scanner head. A minimum distance of $6 \mathrm{ft}$ was required between the scanner and the $\mathrm{C}$-track, so the $\mathrm{C}$-track could not be mounted close to the ceiling to minimize the size of the access panel. The size and location of the access panel also needed to change with different airfoil models. The scanner operator also must be careful not to block the line of sight between the scanner and the C-track. The armless systems were easier to manipulate and provided a greater freedom of motion for the scanner, when compared to the arm-based systems. Another advantage of the two Creaform scanners was that the part of the scanning system that was brought into the test section did not have any moving parts. When using the arm-based systems, the entire arm (with the complex joints and encoders) must be brought into the test section. Although no reliability issues were observed with the arm-based scanners during the IRT evaluations, it is not known what effect (if any) repeated exposure to the IRT test section environment would have on the scanners.

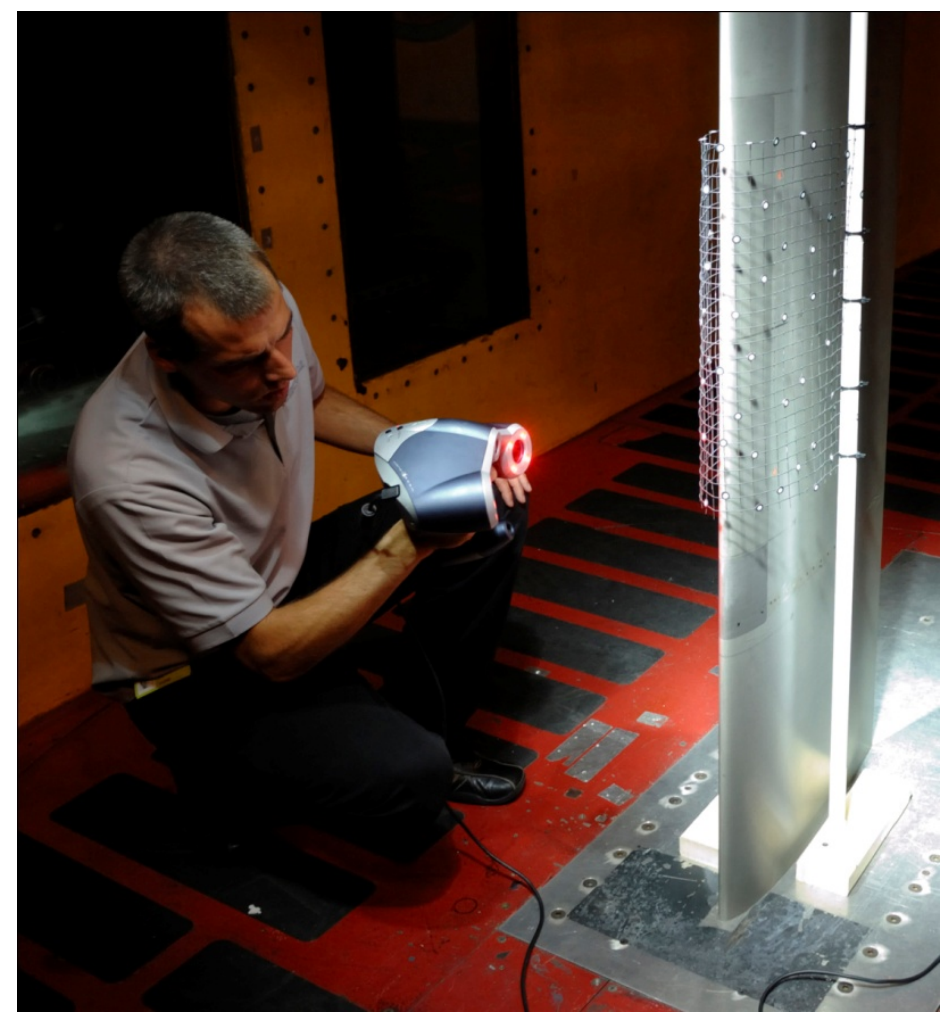

Figure 5.-Creaform HandyScan system. 


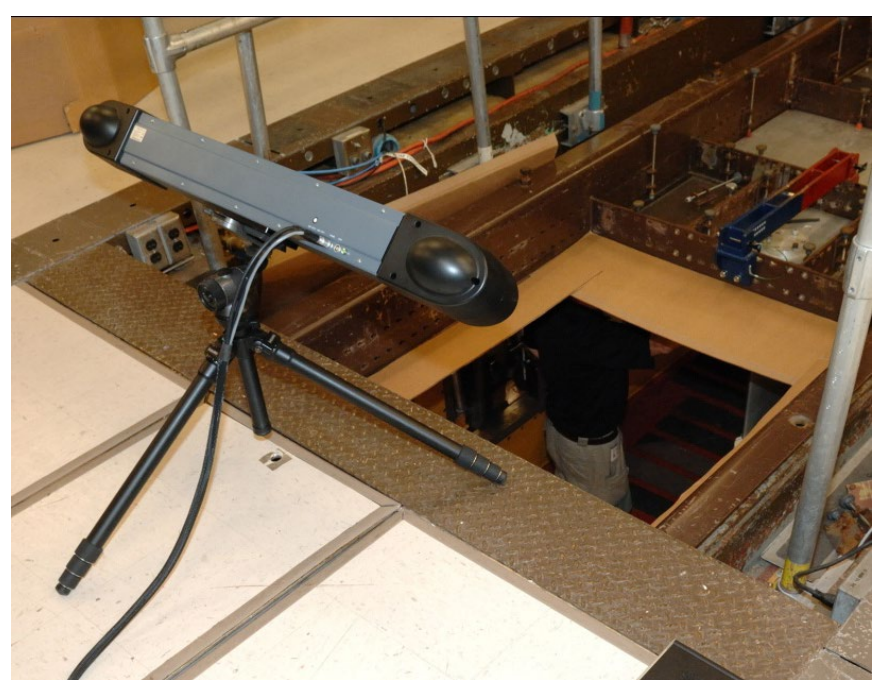

Figure 6.-Creaform C-track system.

Among the arm-based scanners, there were differences between them as well, some of them significant. The Faro Quantum arm was equipped with relative position encoders, which required ranging of the arm every time it was turned on. The Romer and NVision arms were equipped with absolute encoders and did not require ranging upon power up. Although this was an additional step, it could be completed in a few seconds and did not significantly affect the workflow.

Hard-probing of known reference points on the model may be a required step when using an armbased scanner. Faro and NVision system allowed the user to leave the hard-probe on the scanner at all time. On the Romer system, the hard probe must be removed when the scanner is being used. Again, this is an additional operating step, but it could be completed in a few seconds and was not considered significant.

The evaluations of the three arm-based scanners showed that the two Romer based arms were significantly easier to position and manipulate than the Faro arm in the IRT. Both arms used counterbalancing systems to lessen the load on the user. However, it was the opinion of the NASA evaluators that the Romer system was superior for purposes of this research project. This was considered an important factor as it would reduce operator fatigue during the scans and lead to steadier, more accurate scans.

The temperature compensation on the Faro arm worked well for most conditions. However, when the scanner was used at a test section temperature near $0{ }^{\circ} \mathrm{F}$, the scanner outputted a temperature fault error. It was not known if this was due to the temperature being too low, or the temperature of the arm decreasing faster than it could be compensated for. Repeated attempts to use the scanner at this temperature resulted in the same fault message. This temperature is well outside of the manufacturer's stated minimum operating temperature of $50^{\circ} \mathrm{F}$. However, all of the other scanners that were evaluated in the IRT test conditions were able to operate near $0{ }^{\circ} \mathrm{F}$ without any issue (even though none of the scanners was rated to operate this cold).

All of the scanners that were evaluated provided a "real-time" feedback on the status of the scan on the scanner computer screen. The operator could look at the quality and completeness of the scan as the ice shape was being scanned. Additional useful information that was displayed on the computer screen was the whether or not the object being scanned was in focus. The Romer scanner provided an additional useful feature by projecting a focusing dot on the object being scanned. The operator could be aware of the scanner focus state without having to turn and look at the computer screen.

Another significant difference among the scanners was the format of the scan data. All of the armbased scanners outputted point cloud data that could be further processed into a surface data using the software of choice. However, the two Creaform scanners did not output point-cloud data. Instead, the data was already in a semi-processed triangular surface mesh, and the user did not have access to raw, unprocessed point-cloud data. This was considered by NASA evaluators to be a significant limitation because it does not allow the user to work directly with raw, unprocessed data. 


\section{Scanner Selection}

After a review of the evaluation results, the consensus among the NASA evaluators was that an armbased scanning system was better suited for further development for IRT. It required minimal modifications to the test section, resulting in fewer risks in implementation for use. All of the arm-based systems generated "raw" data in an unprocessed state, allowing more control over post-processing of the scan data. Of the arm based systems, the Romer Absolute was considered the most promising. The Faro arm had two significant deficiencies that the Romer arm did not. Due to temperature compensation errors, it could not be used at temperature near $0^{\circ} \mathrm{F}$. Also, its counterbalancing system was found to be less effective than on the Romer arm. The NVision system's arm was nearly identical to that of the Romer Absolute. However, during the IRT evaluation, the scanner had difficulties acquiring ice shape features. It was not known if this was due to scanner limitations or scanner malfunction. Because it did not demonstrate to satisfactorily acquire ice shapes during the IRT demo, the NVision system was not selected.

\section{Lessons Learned}

One of the lessons learned during the scanner evaluation was that reference targets were required on the airfoil model. Without these reference targets, one cannot determine what part of the airfoil model the scans are from. With the two Creaform scanners simple reflective dot stickers were placed on the airfoil model where ice was not expected. For the arm-based systems a physical reference features (such as holes, spheres, etc.) must be machined into the airfoil model (to be either scanned or hard probed). Since the airfoil models used during the scanner evaluation were not specifically built for 3-D scanners, these features were not present during the evaluation. The only reference that was taken with the arm-based scanners was the test section floor plane. Because of this, only the spanwise location of the ice shape (with respect to the airfoil model) was known. The location of the ice shape in the axis of the airfoil chord and thickness was not known for the ice shapes that were scanned with the arm-based scanners. When the data were post-processed, an attempt was made to visually align the ice shape with the airfoil model by matching the portion of the scan that did not have ice (i.e., uniced sections of the airfoil) with the airfoil model. However, this was only an approximate fit and the accuracy of this method was uncertain.

For future tests, the airfoil models will have reference targets machined onto the surface at multiple locations. Initial tests have shown that counter-sunk holes serve as excellent reference points for use with hard probes. If precisely machined, very repeatable hard-probing of the reference points can be achieved. This method will be utilized during the validation and implementation phase of this research program.

\section{Sample Evaluation Data}

Included in this section is a sample of the data from the scanner evaluation. The data shown below were obtained during the evaluation of the Faro Quantum Arm. The results are shown only as a general indication of typical results one would expect from a modern 3-D laser scanning system and software.

There were four general steps in the post-processing of the scan data: alignment, merge, wrap, and hole filling. The first step was to align the sets of point cloud data that make up the scanned object using a best-fit method of the overlapping areas. The second step was to merge the aligned data sets into a single data set, removing overlapping data points. The third step was to wrap a surface over the point-cloud data, turning it into a triangular mesh. The final step was to fill the holes that have formed in the triangular mesh due to gaps in the scan data, making the surface water-tight. In Geomagic, all four steps were largely automated except for the filling of the holes for complex ice geometry, such as the scallop shapes that form on swept wings. For these ice shapes, the gaps and holes were too large and numerous for an automated method, and a manual intervention was required, significantly increasing the time required for the post-processing of the data. Typically, a $1 \mathrm{ft}$ spanwise section of ice shape from the scanner evaluation could be post-processed into a water-tight surface in $1 \mathrm{hr}$. However, large scallop ice shapes required as 
much as $6 \mathrm{hr}$ because many of the holes had to be filled manually. For most ice shapes, the final watertight surface mesh (covering a $1 \mathrm{ft}$ section of airfoil span) contained 1 million triangles.

Figure 7 to Figure 10 show the horn ice shape, roughness shape, streamwise shape, and 3-D scallop shape respectively. Figures on the left show the 3-D scan data after they have been fully processed and converted into a "water-tight" surface. The figures on the right show the photographs of the same ice shapes. These results show the scanner was able to capture many of the details of the ice, even for very complicated shapes such as scallop ice shown in Figure 10. An aerodynamic verification study planned in the Phase II of this program will determine if it has captured all of the aerodynamically relevant features.

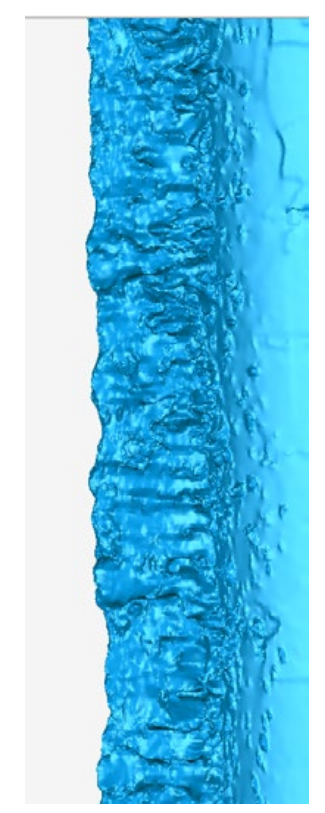

(a)

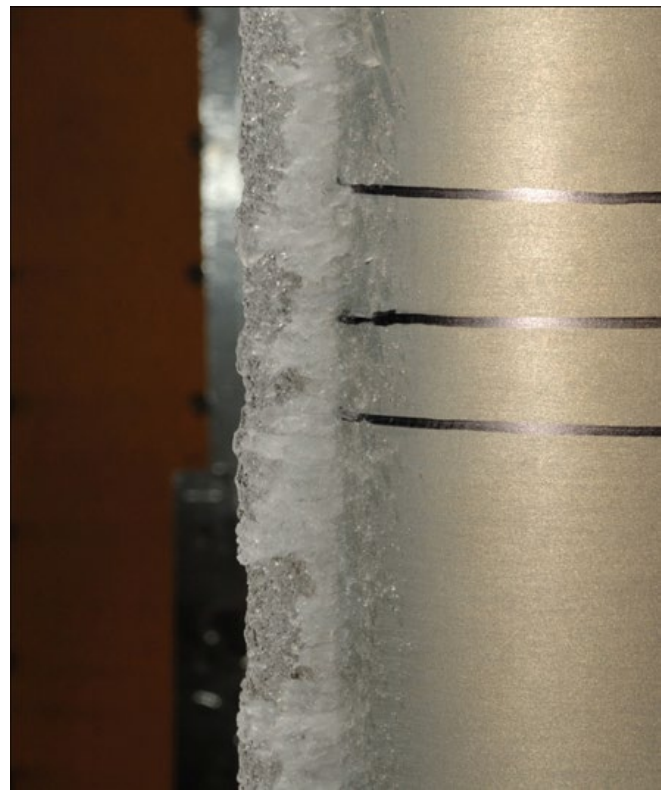

(b)

Figure 7.-Horn ice shape. (a) 3-D Scan. (b) Photograph.

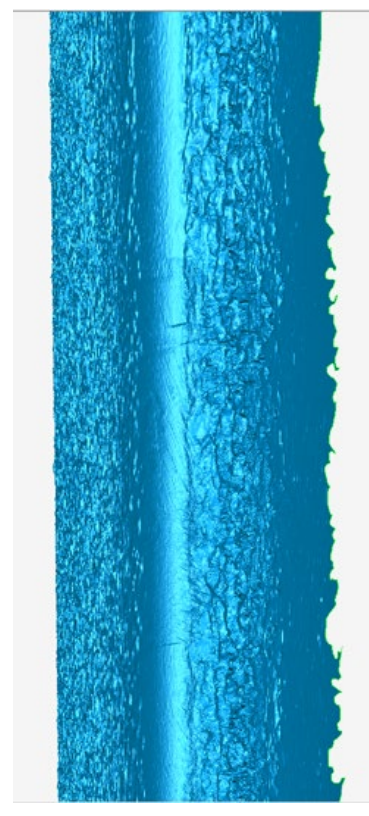

(a)

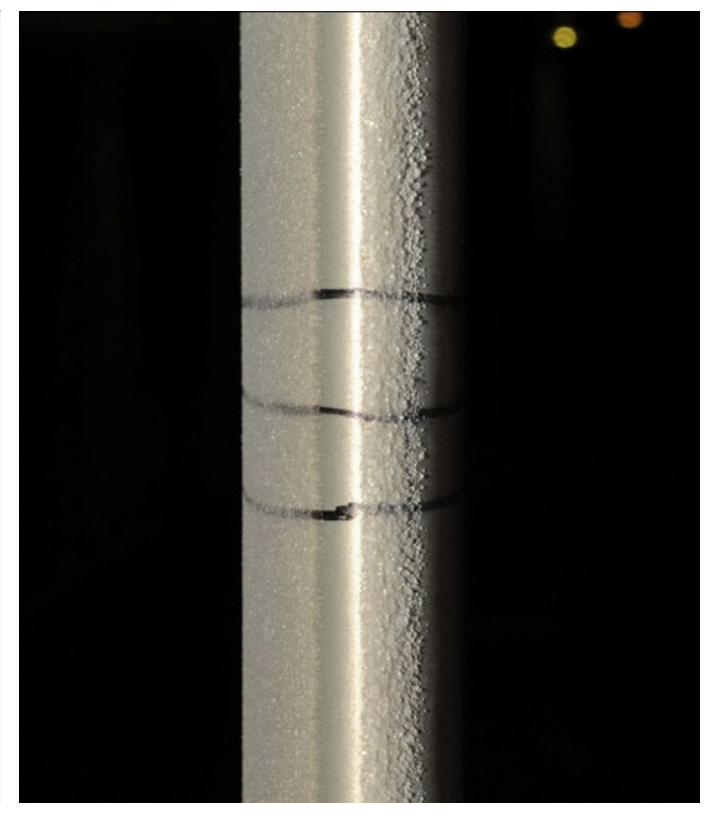

(b)

Figure 8.-Roughness ice shape. (a) 3-D Scan. (b) Photograph. 


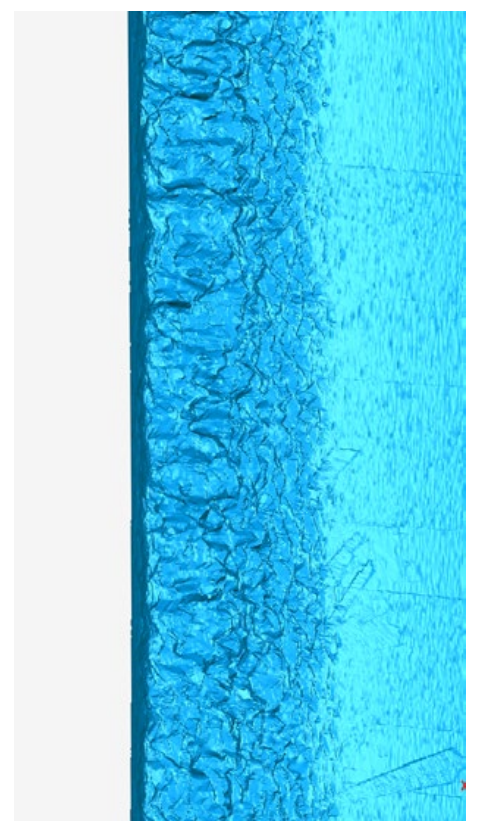

(a)
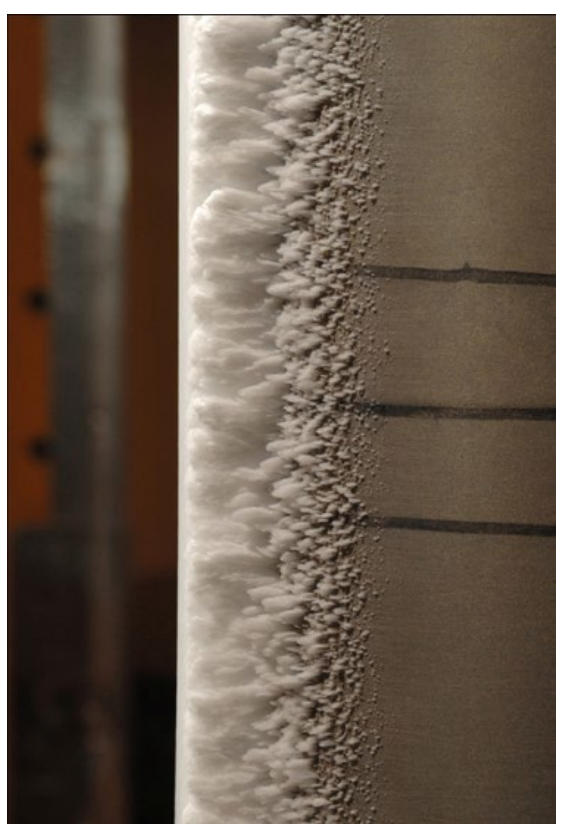

(b)

Figure 9.-Streamwise shape. (a) 3-D Scan. (b) Photograph.

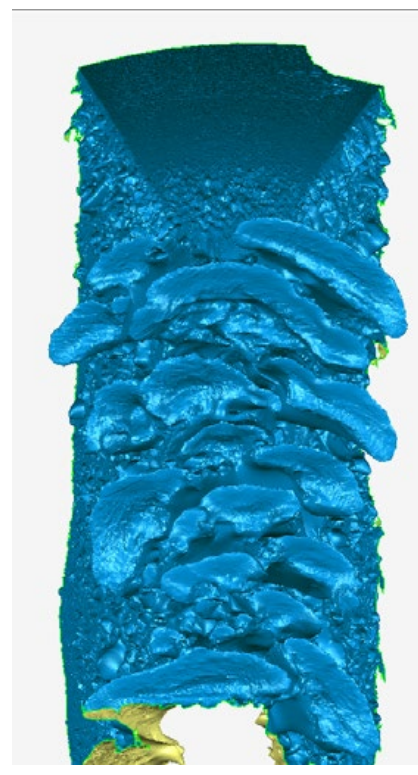

(a)

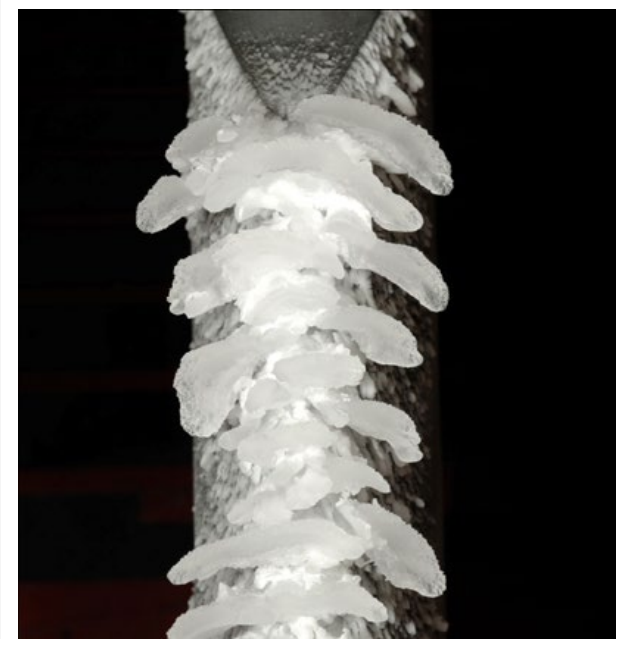

(b)

Figure 10.-3-D scallop shape. (a) 3-D Scan. (b) Photograph.

Figure 11 shows the comparison of the scan data to the 2-D pencil tracing. It shows the $2-\mathrm{D}$ section cuts of the 3-D scan data at the same spanwise location that the hand tracings were made. Figure 11(a) shows the horn ice shape, and Figure 11(b) shows the streamwise ice shape. The results show that the $3-\mathrm{D}$ scan data agreed very favorably with the $2-\mathrm{D}$ hand tracings. It is important to note that the scan data was obtained using the Faro arm, and only the spanwise location of the scan was known due to a lack of reference locations on the model. The scan data were visually aligned with the airfoil by fitting the clean model portion of the scan to the airfoil coordinates. In future work, reference targets will be built into the airfoil model so that the location of the scan will be known in all three axis, with respect to the airfoil. 


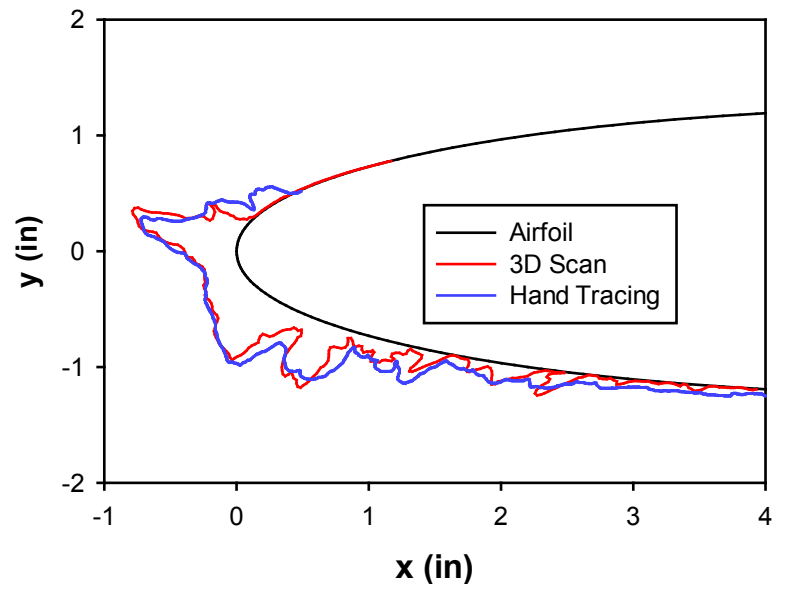

(a)

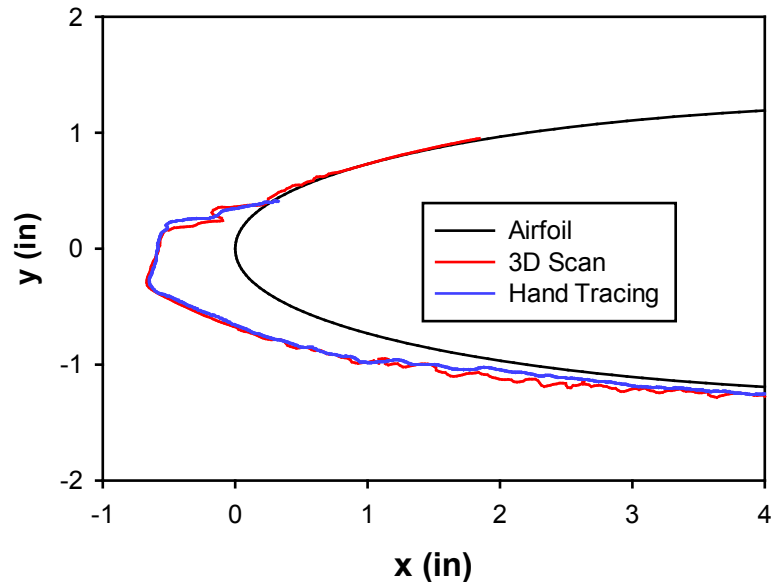

(b)

Figure 11.—Comparison of scan data to hand tracing. (a) Horn ice shape. (b) Streamwise ice shape.

\section{Initial Rapid Prototype Method Assessment}

An initial assessment of the ability to accurately reproduce the scanned ice shapes using rapid prototype methods (RPM) was performed based largely upon published general information of the methods. Three rapid prototype methods were considered for evaluation: selective laser sintering (SLS), stereo-lithography (SLA), and PolyJet. All three methods use lasers to build up layers of material until the process is completed. Table 3 shows the properties of the three rapid prototype methods. PolyJet had the highest resolution and accuracy and was chosen for initial assessment. A 3-D scan file of an ice shape was sent to a company specializing in RPM manufacturing and $1 / 3$ and $1 / 5$ scale samples of the ice shapes were made. One of the goals of using a 3-D scanner is to develop the ability to geometrically scale the ice shapes from the IRT for use in a smaller aerodynamic wind tunnel. It was not known whether current RPM processes had enough resolution and accuracy to reproduce an ice shape that captured all of the aerodynamically important features. It was also not known if the RPM process could be used to geometrically scale down an ice shape while preserving all of the relevant features. This initial assessment was performed to answer some of those questions using the scallop ice shape scan shown in Figure 10. Figure 12(a) shows $1 / 3$ and $1 / 5$ scale RPM shapes next to the full-scale shape obtained using the mold and casting method. Figure 12(b) shows the close up view of the RPM shapes. A qualitative visual assessment indicated that the RPM process (even at these scales) was able to capture the gross aerodynamic features like scallops and large feathers, but not the roughness features (which are on the order of 0.5 to $1 \mathrm{~mm}$ on the full-scale ice shape). A thorough quantitative assessment is required (and will be performed) to fully assess the capability of the current RPM methods.

TABLE 3.-PROPERTIES OF RAPID PROTOTYPE METHODS

\begin{tabular}{|c|c|c|}
\hline Process & $\begin{array}{c}\text { Min. layer thickness, } \\
\text { in }\end{array}$ & $\begin{array}{c}\text { Tolerance, } \\
\text { in. }\end{array}$ \\
\hline SLS & 0.03 & \pm 0.015 \\
\hline SLA & 0.005 & \pm 0.015 \\
\hline PolyJet & 0.0003 & \pm 0.005 \\
\hline
\end{tabular}




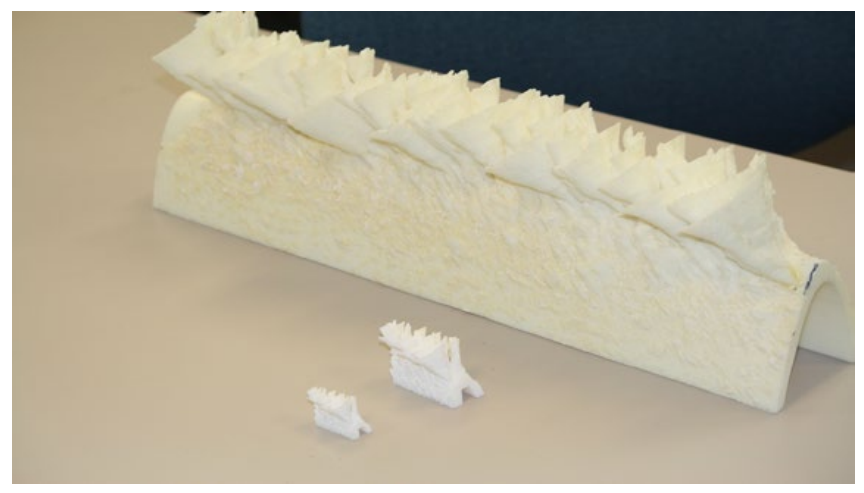

(a)

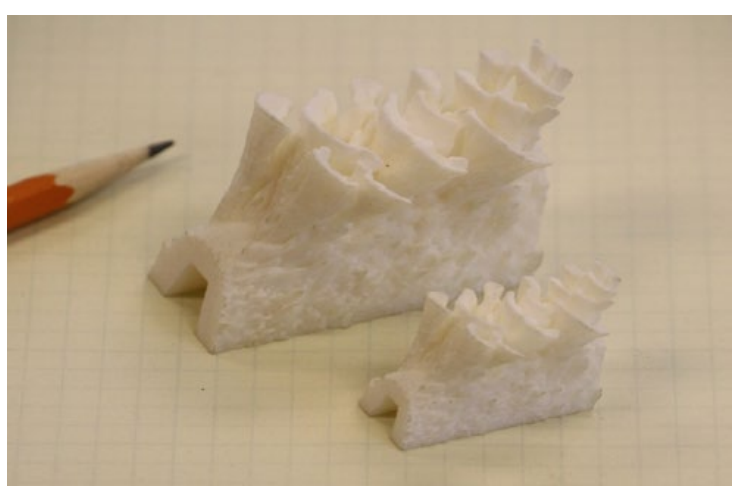

(b)

Figure 12.-PolyJet rapid prototype shapes. (a) Full, $1 / 3$, and $1 / 5$ scale shapes (b) Closeup of $1 / 3$ and $1 / 5$ scale RPM shapes.

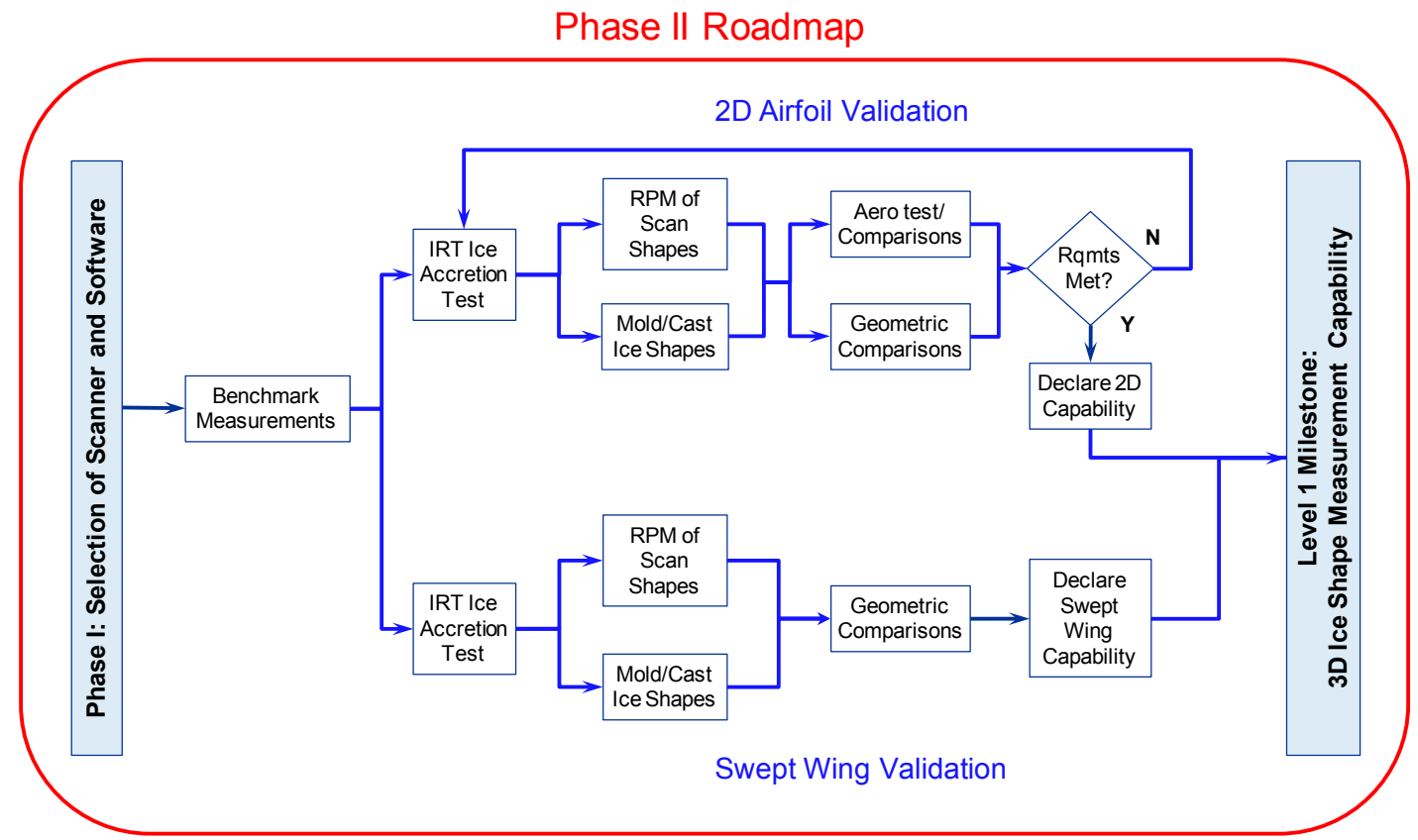

Figure 13.-Phase II of the research plan.

\section{Future Work}

The second phase of this research will focus on the implementation and validation of the 3-D scanning system that was selected in the first phase of the program. The Phase II was built on the methodology developed by Broughton (Ref. 8) during the previous attempt at developing a 3-D scanning capability for the IRT, but it will be greatly expanded upon. The implementation tasks involve developing procedures for using the scanner in the IRT as well as for post-processing the data. An expected outcome of this phase is a document that describes these procedures. This should include all aspects of the measurement including preparation of the ice accretion, set-up of the scanner, scanning of the ice, saving of the data, and finally post-processing of the data. This comprehensive document will serve as an internal reference guide for the continued use of the scanner in IRT. The roadmap for Phase II is shown on Figure 13. 


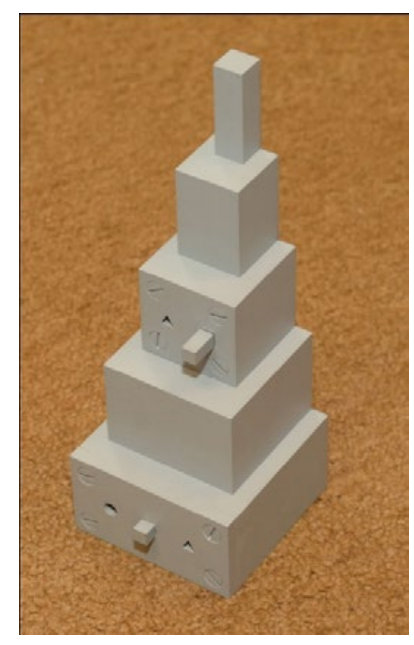

(a)

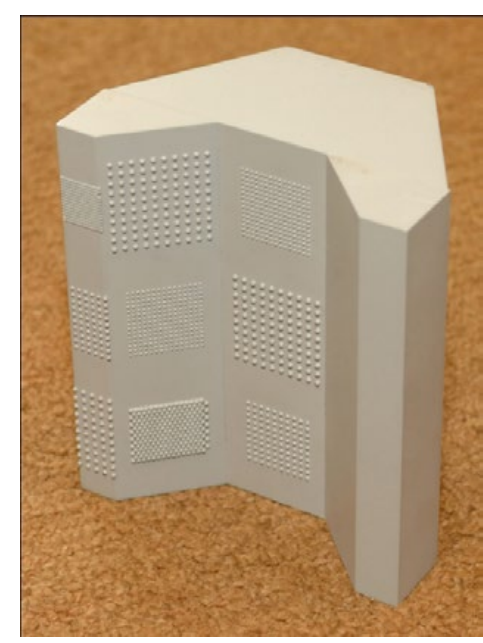

(b)

Figure 14.-Scanner calibration geometries. (a) Metal calibration block. (b) Roughness sample block.

The first step in the Phase II of the research is a series of validation exercises that will be conducted to help define the measurement capability of the scanning system that was identified and purchased during Phase I. Benchmark measurements will be performed on a metal calibration block and a metal "roughness sample" block (Figure 14) using the methodology established by Broughton (Ref. 8). The calibration data will be stored and used as a benchmark reference for future evaluations of the system. These data can be used as a type of check standard to ensure uniform capability over time.

The main component of the validation (as shown in Figure 13) is the "circular" geometric and aerodynamic assessment on a $2-\mathrm{D}$ airfoil geometry. This exercise will consist of comparing scanned ice shapes to castings of the same ice shape. Currently the only means of recording fully 3-D ice shapes is the mold and cast method. The scan data can also be used to create a RPM artificial shape that can be scanned and compared to the original ice accretion. Performing these comparisons will help define the system accuracies and the propagation of uncertainties through the manufacture of artificial ice shapes. It will also help define the limitations of the scanner hardware, software and rapid prototyping. A closely related aerodynamic evaluation will also be conducted, where RPM artificial shapes made from ice scans are compared against ice-shape castings in an aerodynamic wind tunnel. These validations (both geometric and aerodynamic) will be conducted for each of the four basic categories of ice accretion: roughness, horn, streamwise and spanwise ridge as differences in measurement accuracy have different implications in terms of the resulting aerodynamics for different ice shapes (Ref. 3 and 15).

Finally, a geometric validation test will be performed on a 3-D, swept-wing geometry. This is specifically intended to quantify the limitations of capturing very complicated scallop geometries and develop methods to ameliorate these limitations. This research will be documented in a final report that clearly defines the 3-D ice accretion measurement capability.

\section{Conclusion}

A research program is currently being implemented to develop and validate the use of a commercial 3-D laser scanning system to record ice accretion shapes in the NASA Icing Research Tunnel. Phase I of the research was conducted to identify the most suitable laser scanning hardware and software for further development. Phase II of the research is to implement the system and validate its capability to record all of the aerodynamically relevant features. Phase I has been completed, and Phase II is currently underway.

The results of Phase I showed that commercial 3-D laser scanners were capable of recording many details of various types of ice shapes, and post-processing software were capable of generating "water- 
tight" surfaces. The scanners that were evaluated in the IRT had similar abilities to digitize ice shapes because the scanning methods are identical. The primary differences were the method that each system used to position the scanner and the ability to operate in the IRT test section environment. Several scanning systems were evaluated against selection criteria, and an arm-based system was found to be the most promising. This scanner system will be used to implement and validate the use of this technology through a series of icing and aerodynamic tunnel tests.

With continued success of this plan in Phase II, a suitable means of recording and archiving fully 3-D descriptions of experimental ice accretion geometry will have been developed. This will contribute to achieving the main goal of the Airframe Icing Technical Challenge of the NASA Aviation Safety Program: acceptance of experimental and computational icing simulation tools in supercooled large droplet (SLD) conditions and on 3-D airframe components, including swept wings.

\section{References}

1. “Calibration and Acceptance of Icing Wind Tunnels," SAE ARP 5905, SAE International, Warrendale, PA, Sept. 18, 2003.

2. Bosetti, C., Paul, B.P., Jr., Malone, A.M., "Ice Shape Characterization to Aid in Replicating Ice Shapes for Subsequent Analysis," AIAA Paper 2010-7534.

3. Broeren, A.P., Addy, H.E., Jr., Bragg, M.B., Busch, G.T., Guffond, D., and Montreuil, E., "Aerodynamic Simulation of Ice Accretion on Airfoils," NASA/TP-2001-216929, June 2011.

4. Anderson, D.N., Hentschel, D.B., and Ruff, G.A., "Measurement and Correlation of Ice Accretion Roughness," AIAA Paper 98-0486, Jan. 1998, also NASA/CR-2003-211823, June 2003.

5. Shin, J., "Characteristics of Surface Roughness Associated with Leading Edge Ice Accretion," AIAA Paper 94-0799, Jan. 1994, also NASA TM-106459, Jan. 1994.

6. Mikkelsen, K., Juhasz, N., Ranaudo, R., McKnight, R., Freedman, R., and Greissing, J., "In-Flight Measurements of Wing Ice Shapes and Wing Section Drag Increases Caused by Natural Icing Conditions," NASA TM-87301, Apr. 1986.

7. Reehorst, A.L., and Richter, G.P., "New Methods and Materials for Molding and Casting Ice Formations," NASA TM-100126, Sept. 1987.

8. Broughton, H., “3D Laser Scanner Project," Subcontract No. 011422 Report, Feb. 2004.

9. Akca, D., Remondino, F., Novak, D., Hanusch, T., Schrotter, G., and Gruen, A., "Performance Evaluation of a Coded Structured Light System for Cultural Heritage Applications," Videometrics IX, Proceedings of the SPIE, Vol. 6491, pp. 64910V, 2007.

10. Remondino, F., Girardi, F., Gonzo, L., Nicolis, F., "Detailed 3D Reconstruction of the Great Inscription of Gortyna, Crete: Acquisition, Registration, and Visualization of Multi-Resolution Data," Proc. of 14th Int. Conference on Virtual Systems and MultiMedia (VSMM 2008), pp. 404-412, 2008.

11. Colantonio, R., "Atmospheric Environment Safety Technologies (AEST) Project Overview," NASA Aviation Safety Program Annual Technical Meeting, St. Louis, MO, May 10-12, 2011.

12. Potapczuk, M., "Airframe Icing Technical Challenge," NASA Aviation Safety Program Annual Technical Meeting, St. Louis, MO, May 10-12, 2011.

13. Lee, S., "Status of 3D Ice Shape Measurement Effort," NASA Aviation Safety Program Annual Technical Meeting, St. Louis, MO, May 10-12, 2011.

14. Soeder, R.H., Sheldon, D.W., Ide, R.F., Spera, D.A., and Andracchio, C.R, "NASA Glenn Icing Research Tunnel User Manual," NASA/TM-2003-212004.

15. Bragg, M.B., Broeren, A.P., and Blumenthal, L.A., "Iced-Airfoil Aerodynamics," Progress in Aerospace Sciences, Vol. 41, No. 5, July 2005, pp. 323-418. 


\begin{tabular}{|c|c|c|}
\hline \multicolumn{2}{|c|}{ REPORT DOCUMENTATION PAGE } & $\begin{array}{l}\text { Form Approved } \\
\text { OMB No. 0704-0188 }\end{array}$ \\
\hline \multicolumn{3}{|c|}{$\begin{array}{l}\text { The public reporting burden for this collection of information is estimated to average } 1 \text { hour per response, including the time for reviewing instructions, searching existing data sources, gathering and maintaining the } \\
\text { data needed, and completing and reviewing the collection of information. Send comments regarding this burden estimate or any other aspect of this collection of information, including suggestions for reducing this } \\
\text { burden, to Department of Defense, Washington Headquarters Services, Directorate for Information Operations and Reports (0704-0188), } 1215 \text { Jefferson Davis Highway, Suite } 1224 \text {, Anlington, VA } 22222-2302 \text {. } \\
\text { Respondents should be aware that notwithstanding any other provision of law, no person shall be subject to any penalty for failing to comply with a collection of information if it does not display a currently valid OMB } \\
\text { control number. } \\
\text { PLEASE DO NOT RETURN YOUR FORM TO THE ABOVE ADDRESS. }\end{array}$} \\
\hline $\begin{array}{l}\text { 1. REPORT DATE (DD-MM-YYYY) } \\
01-09-2012\end{array}$ & $\begin{array}{l}\text { 2. REPORT TYPE } \\
\text { Technical Memorandum }\end{array}$ & 3. DATES COVERED (From - To) \\
\hline \multirow{3}{*}{\multicolumn{2}{|c|}{$\begin{array}{l}\text { 4. TITLE AND SUBTITLE } \\
\text { Development of 3-D Ice Accretion Measurement Method }\end{array}$}} & 5a. CONTRACT NUMBER \\
\hline & & 5b. GRANT NUMBER \\
\hline & & 5c. PROGRAM ELEMENT NUMBER \\
\hline \multirow{3}{*}{\multicolumn{2}{|c|}{$\begin{array}{l}\text { 6. AUTHOR(S) } \\
\text { Lee, Sam; Broeren, Andy, P.; Addy, Harold, E., Jr.; Sills, Robert; Pifer, Ellen, M. }\end{array}$}} & 5d. PROJECT NUMBER \\
\hline & & 5e. TASK NUMBER \\
\hline & & $\begin{array}{l}\text { 5f. WORK UNIT NUMBER } \\
\text { WBS 648987.02.03.03.10 }\end{array}$ \\
\hline \multicolumn{2}{|c|}{$\begin{array}{l}\text { 7. PERFORMING ORGANIZATION NAME(S) AND ADDRESS(ES) } \\
\text { National Aeronautics and Space Administration } \\
\text { John H. Glenn Research Center at Lewis Field } \\
\text { Cleveland, Ohio 44135-3191 }\end{array}$} & $\begin{array}{l}\text { 8. PERFORMING ORGANIZATION } \\
\text { REPORT NUMBER } \\
\text { E-18389 }\end{array}$ \\
\hline \multirow{2}{*}{\multicolumn{2}{|c|}{$\begin{array}{l}\text { 9. SPONSORING/MONITORING AGENCY NAME(S) AND ADDRESS(ES) } \\
\text { National Aeronautics and Space Administration } \\
\text { Washington, DC 20546-0001 }\end{array}$}} & $\begin{array}{l}\text { 10. SPONSORING/MONITOR'S } \\
\text { ACRONYM(S) } \\
\text { NASA }\end{array}$ \\
\hline & & $\begin{array}{l}\text { 11. SPONSORING/MONITORING } \\
\text { REPORT NUMBER } \\
\text { NASA/TM-2012-217702 }\end{array}$ \\
\hline \multicolumn{3}{|c|}{$\begin{array}{l}\text { 12. DISTRIBUTION/AVAILABILITY STATEMENT } \\
\text { Unclassified-Unlimited } \\
\text { Subject Category: } 02 \\
\text { Available electronically at http://www.sti.nasa.gov } \\
\text { This publication is available from the NASA Center for AeroSpace Information, 443-757-5802 }\end{array}$} \\
\hline
\end{tabular}

\section{SUPPLEMENTARY NOTES}

\section{ABSTRACT}

A research plan is currently being implemented by NASA to develop and validate the use of a commercial laser scanner to record and archive fully three-dimensional (3-D) ice shapes from an icing wind tunnel. The plan focused specifically upon measuring ice accreted in the NASA Icing Research Tunnel (IRT). The plan was divided into two phases. The first phase was the identification and selection of the laser scanning system and the post-processing software to purchase and develop further. The second phase was the implementation and validation of the selected system through a series of icing and aerodynamic tests. Phase I of the research plan has been completed. It consisted of evaluating several scanning hardware and software systems against an established selection criteria through demonstrations in the IRT. The results of Phase I showed that all of the scanning systems that were evaluated were equally capable of scanning ice shapes. The factors that differentiated the scanners were ease of use and the ability to operate in a wide range of IRT environmental conditions.

\section{SUBJECT TERMS}

Icing; Wind tunnel; Aerodynamics

\begin{tabular}{|c|c|c|c|c|}
\hline \multicolumn{3}{|c|}{ 16. SECURITY CLASSIFICATION OF: } & \multirow{2}{*}{$\begin{array}{l}\text { 17. LIMITATION OF } \\
\text { ABSTRACT } \\
\text { UU }\end{array}$} & \multirow{2}{*}{$\begin{array}{l}\text { 18. NUMBER } \\
\text { OF } \\
\text { PAGES } \\
24\end{array}$} \\
\hline $\begin{array}{l}\text { a. REPORT } \\
U\end{array}$ & $\begin{array}{l}\text { b. ABSTRACT } \\
U\end{array}$ & $\begin{array}{l}\text { c. THIS } \\
\text { PAGE } \\
\text { U }\end{array}$ & & \\
\hline
\end{tabular}

19a. NAME OF RESPONSIBLE PERSON STI Help Desk (email:help@sti.nasa.gov) 19b. TELEPHONE NUMBER (include area code) 443-757-5802 

